УДК 82.091 (Сравнительно-исторические литературоведческие исследования)

ТЕАТРАЛЬНОСТЬ И МИМИКРИЯ: ОТ ТЕАТРА ЖИВОТНЫХ ДО ШЕКСПИРА

\author{
(c) 2020 В.И. Пимонов
}

Пимонов Владимир Иванович, Ph.D, кандидат филологических наук (Дания), профессор-эмеритус. E-mail: ivpet65@mail.ru

\author{
Институт кино и телевидения (ГИТР). \\ Москва, Россия
}

Статья поступила в редакцию 28.04.2020

\begin{abstract}
Предмет статьи: Статья посвящена проблеме театральности в литературной теории. Объект статьи: В отличие от традиционного определения театральности как совокупности внешних проявлений драматического искусства (сценичность, зрелищность, игра), выраженного бартовской формулой «театр минус текст», предлагается понимание театральности как имманентного свойства структуры художественного текста, т.е. как категории поэтики. Цель проекта: На примерах пьес Шекспира показано, что невербальные средства выразительности театра (жест, поза, костюм, немая сцена, бессловесное действие, пантомима) находят выражение в словесной реакции на них персонажей, по существу в виде пояснительной ремарки (описательный элемент), что отражает неразрывное единство основного текста и метатекста. Для обозначения этого явления вводится понятие текстуальной театральности. Методология работы: В свете двойственности феномена театральности, заключающего в себе как природное, так и эстетическое начало, применен междисциплинарный метод, в частности, обсуждается идея о том, что биологическим прототипом театральности служит мимикрия у животных. Результаты работы: Предлагается формула, которая описывает простейшую модель мимикрии в театральных терминах ролей: «A» (животное-имитатор, «подражатель») выступает перед «В» («оператором»-жертвой обмана) в роли «С» («модель»- объект, которому подражают). Эта же формальную модель, построенная на взаимодествии ролей, предлагается для описания механизма «метапьесы» (инсценировки), как ключевого элемента театральности: «А» выступает перед «В» в роли «С», где «A» - персонаж (в символическом смысле тождественный «имитатору» в мимикрии), который выступает перед персонажем «В» (зрителем - «жертвой обмана»), в роли «С», то есть в роли «другого» персонажа (тождественного «модели» в мимикрии). Приводятся различные варианты воплощения метапьесы в драматургии Шекспира. Также рассматривается риторическое построение «текст в тексте», лежащее в основе ситуации, когда действуюшее лицо, кроме своей основной роли, одновременно выступает в литературно-театральной метароли автора и драматурга, что воспроизодит творческий процесс сочинения текстов внутри произведения. В этой связи прослежена метатеатральная роль Гамлета как драматурга, автора текстов для театра. Область применения результатов: литературоведение, теория литературы, шекспироведение. Вывод: театральность как понятие поэтики является имманентным свойством структуры художественного текста. Автор выражает благодарность Дану Уитману и Светлане Грачевой за обсуждение и советы.

Ключевые слова: театральность, мимикрия, метапьеса, инсценировка, текст в тексте, автор, драматург.
\end{abstract}

DOI: 10.37313/2413-9645-2020-22-71-87-92

Понятие театральности до сих пор не обрело терминологической устойчивости в теории литературы. Слово «театральность» обычно употребляют для обозначения совокупности внешних характеристик драматического искусства, таких как сценичность, зрелищность, игра. Театральность противопоставляют поэтике так же, как театр - литературе [1, с. 407], что находит отражение в классической бартовской формуле «театр минус текст» [2, с. 616]. Между тем театральность, понимаемая как категория поэтики, является имманентным свойством глубинной структуры художественного произведения. Речь идет о «текстуальной театральности», которая не противопоставляется вербальному тексту (литературе), а оказывается его неотъемлемой составляющей. Например, когда невербальные, чисто театральные, сценические способы и средства коммуникации - жест, поза, движение, костюм, немая сцена, бессловесное действие, пантомима - находят выражение в словесной реакции на них персонажей - репликах, описаниях, рассказах, комментариях, по существу выступающих в функции пояснительной сценической ремарки внутри основного драматического текста (описательный, мета-текстовый элемент). 
Текстуальная театральность обнаруживает неразрывное единство текста и метатекста: метатекст оказывается органической частью основного текста, а основной текст не существует без метатекста. Яркие примеры «текстуальной театральности», симбиоза текста и мета-текста мы находим в пьесах Шекспира. Содержание немой сцены, которую Гамлет в жанре пантомимы разыгрывает перед Офелией, передано в ее словесном рассказе Полонию: «Он взял меня за кисть и крепко сжал; / Потом, отпрянув на длину руки, / Другую руку так подняв к бровям, / Стал пристально смотреть в лицо мне, словно / Его рисуя ... »- He took me by the wrist, and held me hard; / Then goes he to the length of all his arm, / And with his other hand thus o'er his brow, / He falls to such perusal of my face / As he would draw it (II.1.101-105). О бессловесной реакции Клавдия на сцену убийства в «Мышеловке» зритель также узнает из реплики Офелии: «Король встает!» (The king rises! III.2.259), которая, по существу, представляет собой сценическую ремарку (метатекст) внутри основного текста. Костюм актера - наиболее заметный невербальный элемент театрального языка, превращается у Шекспира в словесную метафору, когда Клавдий обращается к Гамлету, одетому в черное: «Ты все еще окутан прежней тучей?» (King. How is it that the clouds still hang on you? I.2.66). В комедии «Как вам это понравится» упоминание «пестрого плаща» шута (сценического костюма актера) становится метафорой свободы слова - возможности говорить правду: Jaq. Invest me in my motley; give me leave / To speak my mind (II.7) - Жак. Оденьте в пестрый плащ меня! - Позвольте / Всю правду говорить. Предводитель королевского войска Макбет в одноименной пьесе Шекспира получает весть о том, что «Бирнамский лес идет на Дунсинан» (пер. Ю. Лифшица). Неправдоподобное предсказание сбывается: Макбет терпит поражение и гибнет. Топоним «Бирнамский лес» воплощен на сцене с помощью предмета театрального реквизита, который обозначен в тексте словами «лес» (wood) и «ветка» (bough). В свою очередь, предмет сценического реквизита «ветки», которые являются элементом сценического костюма солдат, становится словесной метафорой, которая актуализируется в реплике о том, что «Бирнамский пошел на Дунсинан»солдаты двинулись под прикрытием веток.

Мимикрия. Сложность выработки строгого определения театральности как понятия поэтики обусловлено его двойственностью. С одной стороны, театральность связывают с естественным, неосознанным или инстинктивным игровым поведением, с другой - со специфическими средствами выражения сценического искусства. Теоретик театра Н.Евреинов, ко- торый еще в 1912 году выдвинул гипотезу о пре-эстетическом «инстинкте театральности», воплощенном в стремлении «как бы <...> превратиться в совершенно иных лиц, <..> стать другим» [3, с. 44, 59], видел в мимикрии «начало всех начал драматических игр у животных», проявление «театра у животных» [4, с. 291, 298]. В тот же период русский философ П. Успенский называл мимикрию у насекомых «театральностью природы» [5, с. 38]. Хотя в современном смысле под театральностью как эстетическом феномене культуры понимают не инстинктивное поведение животных, а сознательное исполнение актером роли, намеренное перевоплощение человека в «другого» перед зрителями [6, с. 194], можно предположить, что биологическим прототипом театральности является мимикрия. Мимикрия могла сыграть роль и в процессе возникновения языка [7, с. 9], который театрален по своей природе: уже в простейшей модели диалога, в том числе внутреннего, говорящий и слушающий меняются ролями, попеременно играя роль «другого» [8, с. 138-139]. Под мимикрией понимают «близкое внешнее сходство одного организма (имитатора) с другим (моделью), которое «обманывает» третьего (оператора)» [9, с. 169], становящегося жертвой хищника. Один из видов мимикрии представляет собой ситуацию, когда съедобный вид, дабы не стать жертвой хищника, с помощью маскировки (изменение окраски, притворная смерть) «имитирует» перед опасным для себя видом (хищником) несъедобный (ядовитый) вид. В агрессивной мимикрии «имитатором» выступает хищник, который имитирует, как правило, с помощью специфического поведения (вибрация паутины, выделение химических веществ, имитирующих половые ферамоны) «другой», «дружественный» вид с целью обмануть и завлечь в ловушку третьего. В ситуации мимикрии возникает три инвариантныхметароли: имитатор (mimic) - вид, который имитирует другой вид; жертва обмана (dupe) - вид, для которого имитатор притворяется другим видом, и модель (model) - вид, который имитатор имитирует (изображает), дабы быть на него похожим [10, с. 229]. Простейшая «мизансцена» мимикрии может быть выражена формулой: «А» (имитатор) выступает перед «В» (жертвой обмана) в роли «С» (модели). Многообразие форм мимикрии в природе связано с разнообразием способов маскировки, что перекликается с феноменом маски в культуре.

Метапьеса. Модель мимикрии, построенная на взаимоотношениях трех обобщенных ролей, может служить основой модели театральности, которая описывается в виде последовательности действий персонажей художественного произведения: один персонаж или группа пер- 
сонажей, выступая вметароли авторов, драматургов, режиссеров и актеров (эти роли отличны от первоначально заданных ролей, например, короля, шута и т.д.), разыгрывают театральную постановку / инсценировку по сочиненному и/ или написанному ими сценарию - с целью обмана или введения в заблуждение другого персонажа или группы персонажей, которые выступают в метароли актеров и зрителей [11, с.24]. По ходу действия между персонажами происходит обмен метаролями: автор, который ставит спектакль для другого персонажа, как правило, в качестве «ловушки», «мышеловки», сам оказывается жертвой собственной инсценировки. Постановщик театральной «мышеловки», расставленной для соперника, сам в нее попадает. Персонажи, выступая в метароли авторов-драматургов, актеров и режиссеров, устраивают инсценировку с цзелью обмана или введения в заблуждение других персонажей, выступающих в роли невольных зрителей или в роли жертвы инсценировки. Обозначим инсценировку или представление, осуществляемые персонажами внутри основного действия драматического произведения, термином метапьеса, которую будем считать минимальной, базовой единицей театральности.

Простейшая метапьеса может быть описана той же формулой, что и модель мимикрии: «А» выступает перед «В» в роли «С» [12, с. 26], где «А»- персонаж пьесы (в символическом смысле тождественный «имитатору»), который выступает перед «В» (персонажем-зрителем, тождественным «жертве обмана») в роли «С», то есть в роли другого персонажа (тождественного «модели»).

Предлагаемая формула, основанная на отношеняях между обобщенными персонажами «А», «В» и «С», позволяет описать самые разнообразные варианты метапьес: «А» выдает себя за «А» перед «С» и становится «В»: Шут играет перед Лиром шута, уже не будучи шутом. «А» предлагает «В» выступить в роли «А»: Лорд навязывает Слаю роль лорда («Укрощение строптивой»). «А» начинает играть роль «С», а потом выясняется, что он на самом деле и есть «С»: Гамлет (A) начинает играть роль сумасшедшего (C), а потом совершает поступки, которые, действительно, воспринимаются как безумные (C), например, убийство Полония. Первая же сцена «Гамлета» представляет собой метапьесу, в которой «А» (Бернардо) выступает перед «В» (Франсиско) в роли «С» (незнакомца). Гамлет (A) выступает перед королем (В) в роли сумасшедшего (C); Призрак (А) выступает перед Гамлетом (В) в роли его убитого отца (C); Убийца Клавдий (A) выступает перед Гамлетом (B) в роли благородного короля (C); Яго (А) выступает перед Отелло (В) в роли друга $(\mathrm{C})$.
Шекспир. Театральность как эстетическая категория находит наиболее яркое выражение в европейской драматургии XVII века: «Благодаря череде имен от Шекспира до Кальдерона и $\mathrm{Pa}$ сина драма главенствовала во всей поэтике столетия. Каждый поэт, в свою очередь, сравнивал мир с театром, где всякий играет свою роль» [13, c. 14]. В поэтике Ренессанса и барокко театральность играет роль универсального мирового языка, становясь фундаментальным принципом драматургии Шекспира. В пьесах Шекспира персонаж не только воплощает авторский замысел, играя заранее предназначенную для него роль, но и сам начинает осознанно выступать в роли автора, режиссера, драматурга, актера или зрителя в метапьесе.

Текст в тексте. Структурным эквивалентом метапьесы служит построение «текст в тексте», которое «обостряет момент игры <..>, а текст приобретает <...> игровой характер <...>, театрализованный смысл» [14, с. 13]. На «тексте в тексте» зиждется построение метапьесы в комедии «Сон в летнюю ночь»: в ходе репетиции вставного спектакля актеры-ремесленники обсуждают написание двух прологов (текстов) для того, чтобы вставить их в текст основной (на самом деле - тоже вставной) пьесы. Первый пролог должен заверить зрителей, что Пирам, совершающий самоубийство по ходу вставной пьесы на самом деле не убивает себя и что никакой он не Пирам, а ткач Основа. Второй пролог сообщает о том, что Лев вовсе не настоящий лев, а просто столяр Мигва. Происходит удвоение приема: «текст в тексте в тексте». В «Отелло» сценарий мести Яго также оказывается метапьесой в виде «текста в тексте»: внутри основного текста Яго сочиняет для Отелло рассказ (текст) о надуманной измене Дездемоны.

Переписчик. «Мышеловка» в «Гамлете» представляет собой «текст в тексте» в буквальном смысле, поскольку Гамлет собирается написать «дюжину или шестнадцать строк» и вставить свой текст в текст старой итальянской пьесы «Убийство Гонзаго». Гамлет - первый герой мировой литературы, который на протяжении всего действия сочиняет письменные тексты для театра. Он пишет письмо Офелии, переписывает (в переносном смысле) сценарий роли Гертруды, сочиненный его соперниками-драматурнами Клавдием и Полонием (III.4), переписывает (в буквальном смысле) письма короля, которые Гильденстерн и Розенкранц везут в Англию, переписывает сценарий мести, предложенный Призраком (не убивает Клавдия при первой возможности), переписывает замысел короля в финальной сцене поединка, отдавая свой голос Фортинбрасу исправляя тем самым «поддельную басню» (a forged process - I.5.37) о смерти старого Гамлета, с помощью которой Клавдий завладел 
троном. В роли «переписчика» Гамлет становится символическим двойником Шекспира, начинавшего как «штопальщик пьес» (playpatcher), который переписывал и переделывал старые тексты других драматургов.

Письма. Выступая в метароли автора-драматурга, Гамлет пишет два письма - Клавдию и Гертруде (после возвращения из морского путешествия): «Гонец. Письма, государь, от принца; / Одно для вас, другое -королеве» («Mess. These to your Majesty, this to the Queen» (IV.7.37)), numem письмо Горацио, передавая его через матроса: «Первый моряк. Тут вам письмо, сударь...» (1st Sail. There' a letter for you, sir, IV.6.8). Написание Гамлетом писем дублируется как в действиях Клавдия, пишущего письмо старому Норвежцу («Мы просим этим / Письмом Норвежца, дядю Фортинбраса» - we have here writ / To Norway, uncle of young Fortinbras, I.2.27), так и в действиях Полония, пишущего письмо Лаэрту, которое он передает через Рейнальдо: «Вот деньги и письмо к нему, Рейнальдо» (Give him this money and these notes, Reynaldo, II.1.1). Письма, написанные персонажами пьесы, - это не эпистолярные опыты, в метафорическом смысле это тексты театральных сценариев, по которым развивается действие.

Сочинитель. В метароли сочинителя, то есть пищущего автора-драматурга, Гамлет выступает уже в самом начале пьесы, когда записывает «в свои таблички» текст о Клавдии. Сразу же после ухода Призрака со словами «Помни обо мне» (Remember me (I.5.91)) принц восклицает: «Подлец, / Улыбчивый подлец, подлец проклятый» (O villain, villain, smiling, damned villain!) - и продолжает: Ham. My tables, - meet it is I set it down, / That one may smile, and smile, and be a villain; / At least I'm sure it may be so in Denmark: [Writes.] / So, uncle, there you are. Now to my word; / It is, 'Adieu, adieu! remember me. / I have sworn't (I.5.115-120). Гамлет. Мои таблички, - надо записать, / Что можно жить с улыбкой и с улыбкой / Быть подлецом; по крайней мере - в Дании. (Пишет.) / Так, дядя, вот вы здесь. - Мой клич отныне: / «Прощай, прощай! И помни обо мне». / Я клятву дал.

«Таблички памяти» (tables of my memory) представляли собой подобие записной книжки (notebook) на сцене - предмет театрального реквизита. Актер, исполнявший роль Гамлета во времена Шекспира, действительно доставал такую записную книжку и делал на ней запись [15, с. 2-3]. Из слов Гамлета следует, что он записывает в таблички текст о дяде: «Так, дядя, вот вы здесь» (So, uncle, there you are) - то есть, ты здесь, в тексте на табличках: «<...> можно жить с улыбкой и с улыбкой / Быть подлецом; по крайней мере - в Дании» (<...> one may smile, and smile, and be a villain; At least I'm sure it may be so in Denmark). В этой сцене Гамлет выступает в метароли автора-драматурга, который пишет пьесу о короле. Намереваясь убедиться в достоверности слов Призрака об убийстве своего отца Клавдием, Гамлет предлагает прибывшим в Эльсинор актерам сыграть старую итальянскую пьесу «Убийство Гонзаго». Если Призрак сообщил правду, то Клавдий выдаст себя во время представления. Принц обращается к Первому актеру: Ham. Dost thou hear me, old friend; can you play the murder of Gonzago? / First Player. Ay, my lord. / Ham. We'll ha't to-morrow night. You could, fo $r$ a need, / Study a speech of some dozen or sixteen lines, which / I would set down and insert in't, could you not? / First Player. Ay, my lord. / Ham. Very well (II.2.377-385). Гамлет. Послушайте, старый друг; можете вы сыграть «Убийство Гонзаго»? / Первый актер. Да, принц. / Гамлет. Мы это представим завтра вечером. Вы могли бы, / если потребуется, выучить монолог в каких-нибудь двенадцать или шестнадцать строк, / которые я бы сочинил и вставил туда? / Могли бы вы? / Первый актер. Да, принц. / Гамлет. Отлично.

Сочиняя монолог (speech) - добавление к «Убийству Гонзаго», то есть по существу, переписывая старую пьесу, Гамлет становится автором новой, уже собственной пьесы под названием «Мышеловка».

Человек театра. Перед поединком с Лаэртом Гамлет говорит Горацио: «Нас не страшат предвестия, и в гибели воробья есть особый промысел»- «We defy augury; there’s a special providence in the fall of a sparrow» (V.2.215). Эти слова - парафраз текста другого автора: переписанные и переработанные Гамлетом слова Иисуса, записанные и переданные неизвестным автором Евангелия [16, с.731], авторство которого приписывают Матфею [17, с. 407]: «Не две ли малые птицы (два воробья) продаются за ассарий? И ни одна из них не упадет на землю без воли Отца нашего» (Матф. 10.29) "Are not two sparrows sold for a farthing. And one of them shall not fall on the ground without your Father» (Matthew 10.29). Обычно эти слова толкуют как притчу о том, что жизнь любого человека зависит от воли Божьей, сам же человек - лишь слуга и орудие в Его руках. Однако Гамлета не устраивает роль марионетки в пьесе другого автора-драматурга, даже если речь идет о Всевышнем. Перед лицом смерти, ведь обладая вещей душой (O, my prophetic soul!), он знает, что погибнет в поединке с Лаэртом, Гамлет переписывает на свой авторский лад фрагмент текста из Священного Писания, до конца оставаясь человеком театра, в котором роль автора-драматурга для него важнее всех других ролей. 
1. Пави, П. Театральность // Пави П. Словарь театра. - М., 2003. - С. 407.

2. Барт, Р. Избранные работы. Семиотика / Ред. и вступ. ст. Г. Косикова. - М., 1994. - С. 616.

3. Евреинов, Н. Н. Демон театральности. - М.; СПб., 2003. - С. 44, 59.

4. Евреинов, Н. Н. Театр животных // Оригинал о портретистах. - М., 2005. - С. 291, 298.

5. Teckyoung Kwon. Mimicry of Fred: Art as Science. Lexington books. London, 2017. - P. 38.

6. Grammatos, Theodoros. Thetricality before the theater. The beginning of theatrical expression / in: Antropoly e Teatro, no. 3 (2012). - P. 194.

7. Robson, D. The origins of language discovered in music, mime and mimicry // New Scientist. May 2019. - P. 9.

8. Brandt Per Aage. Fra gestik til teatralitet — om udsigelsen og kunsten at være synlig // Set fra sidste punktum. Tekst og udsigelse I semiotisk perspektiv. Borgen, Copenhagen 2002. -P. 138-139.

9. Pasteur, G. A Classificatory Review of Mimicry Systems. Ann. Rev. Ecol. Syst. 1982. 13:169-99.

10. Hurley, S., Chater, N. (ed.) Perspectives on Imitation: from Neuroscience to Social Science. Vol. 10. Imitation, Human Development and Culture - Cambridge, Massachusets: The MIT Press, 2005. - P. 229.

11. Пимонов, В., Славутин Е. Загадка Гамлета. - М., 2001. - С. 24.

12. Пимонов, В. Поэтика театральности в творчестве Шекспира. М.: Флинта, 2020. - С. 26.

13. Хейзинга, Й. Homo Ludens. - М., 1991. - С. 14.

14. Лотман, Ю. М. Текст в тексте // Труды по знаковым системам. - Тарту, 1981. - Вып. XIV. -С. 13.

15. Kato, Y. Some Aspects of Elizabethan Staging and Stage Directions // British Council Seminar on Theatre. - Hakone. - 26th September 1990. - P. 2-3.

16. Davies, W., Allison D. A Critical and Exegetical Commentary on the Gospel of Saint Matthew. Volume 1. - Bloomsbury Academic 1988. - P.731.

17. Jenkins, H. Hamlet. The Arden Shakespeare. Methuen 1982. - P. 407.

\title{
THEATRICALITY AND MIMICRY: FROM ANIMAL THEATRE TO SHAKESPEARE
}

\author{
(c) 2020 V.I. Pimonov \\ Vladimir I. Pimonov, Ph.D in Philology (Denmark), professor emeritus. \\ E-mail:ivpet65@mail.ru \\ GITR Film \& Television School. \\ Moscow, Russia
}

Subject of the article: The article discusses the concept of theatricality in literary theory. The object of the article: In contrast to a traditional definition of theatricality as a set of theater-related features (dramatism, visuality, spectatorship and acting) which is reflected in Barthes's classic formulation «theater-minus-text», the author argues that theatricality is indeed an immanent constituent of the structure of a literary and dramatic text. The goal of the research: Using fragments from Shakespeare's plays the author shows how the nonverbal and «purely theatrical» means of expression including gestures, body positions, theatrical costumes, dumb shows, mute scenes and pantomimes manifest themselves in the main text through verbal reactions of the characters (similar to descriptive metatextual stage remarks). The author uses the term «textual theatricality» to describe this of indivisible unity of the main text and meta-text. Research methodology: Taking into account the dichotomy between nature and culture in the phenomenon of theatricality, the author takes an interdisciplinary approach. The article argues that mimicry could be a biological prototype of theatricality. Results: The article offers a formula describing the elementary generalized model of mimicry in terms of theatrical roles: «A» (the mimic) in front of «B» (the dupe, who becomes prey - species being deceived) plays a role of «» (the model - species being mimicked). The author argues that a similar formal model based on the relationship between roles is applicable for the description of a «meta-play» as a key element of theatricality: «A» in front of «B» plays a role of «C», where «A» is a character (equivalent to the «mimic» in mimicry), «B» is a spectator (equivalent to the «prey») and «C» is «someone else» «the third person», «the other» (equivalent to the «model»). The article discusses a rhetorical structure «text within a text» which lies behind a meta-theatrical situation in which a character of the play, along with the main role, plays a meta-literary role of the author and writer, reproducing the creative process of writing within the main text. Hamlet's meta-role as dramatist and playwright is described. Field of application: Literary studies, literary theory, Shakespeare studies. Conclusion: theatricality as a notion of poetics can be defined as an immanent property of literary text. I would like to thank Dan Whitman and Svetlana M. Gracheva for discussions and helpful suggestions.

Key words: theatricality, mimicry, metaplay, dramatization, text within a text, author, dramatist.

DOI: $10.37313 / 2413-9645-2020-22-71-87-92$

1. Pavi, P. Teatral'nost' (Theatricality) // Pavi P. Slovar' teatra. - M., 2003. - C. 407.

2. Bart, R. Izbrannyye raboty. Semiotika (Selected Works. Semiotics) / Red. i vstup. st. G. Kosikova. - M., 1994. C. 616. 
3. Yevreinov, N. N. Demon teatral'nosti (Demon of theatricality). - M.; SPb., 2003. - C. 44, 59.

4. Yevreinov, N. N. Teatr zhivotnykh // Original o portretistakh (Animal Theater // Original about portraitists). - M., 2005. - C. 291, 298.

5. Teckyoung Kwon. Mimicry of Fred: Art as Science. Lexington books. London, 2017. - P. 38.

6. Grammatos, Theodoros. Thetricality before the theater. The beginning of theatrical expression / in: Antropoly e Teatro, no. 3 (2012). - P. 194.

7. Robson, D. The origins of language discovered in music, mime and mimicry // New Scientist. May 2019. - P. 9.

8. Brandt Per Aage. Fra gestik til teatralitet - om udsigelsen og kunsten at være synlig // Set fra sidste punktum. Tekst og udsigelse I semiotisk perspektiv. Borgen, Copenhagen 2002. -P. 138-139.

9. Pasteur, G. A Classificatory Review of Mimicry Systems. Ann. Rev. Ecol. Syst. 1982. 13:169-99.

10. Hurley, S., Chater, N. (ed.) Perspectives on Imitation: from Neuroscience to Social Science. Vol. 10. Imitation, Human Development and Culture - Cambridge, Massachusets: The MIT Press, 2005. - P. 229.

11. Pimonov, V., Slavutin Ye. Zagadka Gamleta (The riddle of Hamlet). - M., 2001. - S. 24.

12. Pimonov, V. Poetika teatral'nosti v tvorchestve Shekspira (The poetics of theatricality in the works of Shakespeare). M.: Flinta, 2020. - S. 26.

13. Kheyzinga, Y. Homo Ludens. - M., 1991. - C. 14.

14. Lotman, YU. M. Tekst v tekste // Trudy po znakovym sistemam (Text in the text // Transactions on sign systems). Tartu, 1981. - Vyp. XIV. -C. 13.

15. Kato, Y. Some Aspects of Elizabethan Staging and Stage Directions // British Council Seminar on Theatre. - Hakone. - 26th September 1990. - P. 2-3.

16. Davies, W., Allison D. A Critical and Exegetical Commentary on the Gospel of Saint Matthew. Volume 1. Bloomsbury Academic 1988. - P.731.

17. Jenkins, H. Hamlet. The Arden Shakespeare. Methuen 1982. - P. 407. 